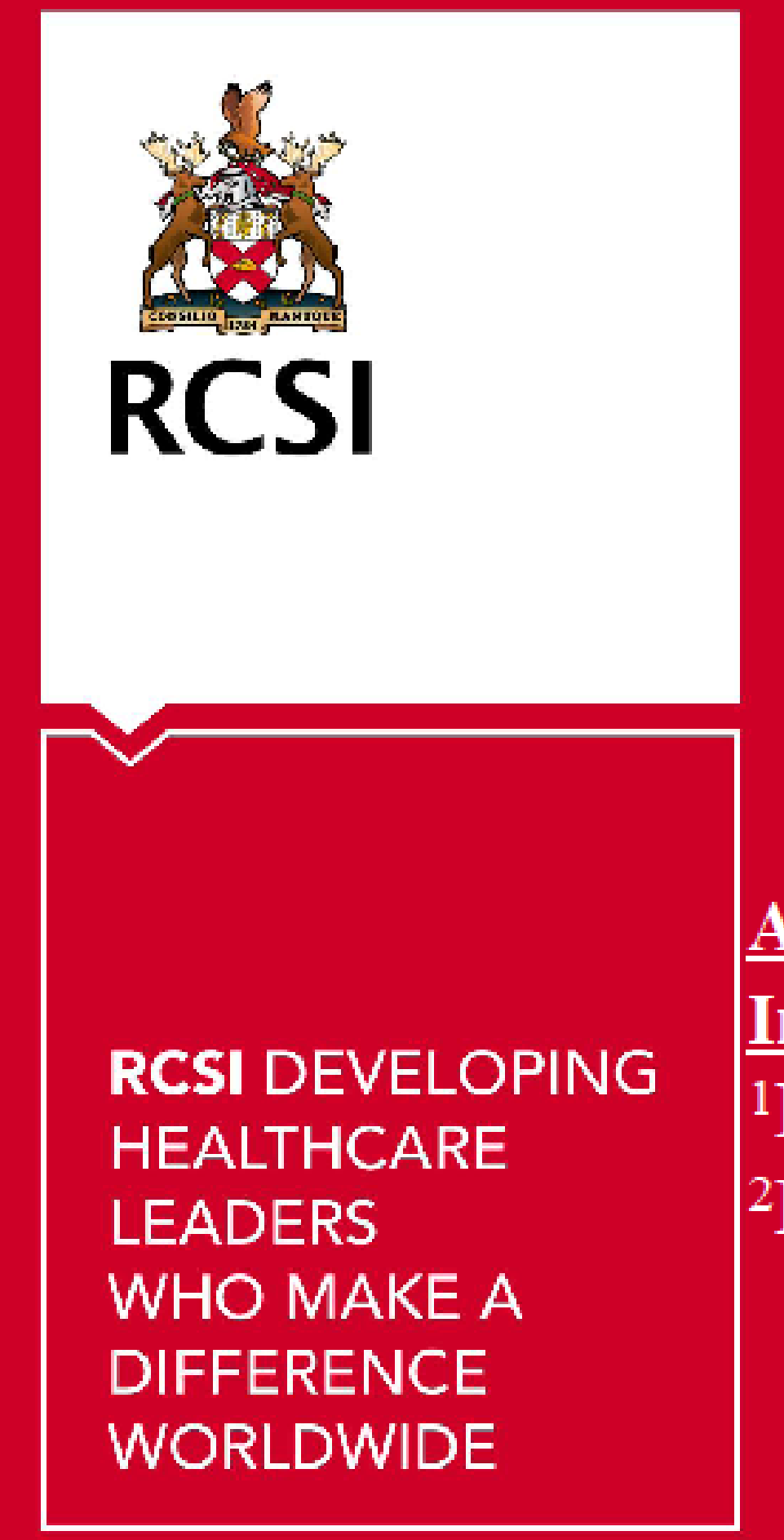

THE INCIDENCE OF CENTRAL ADRENAL INSUFFICIENCY IN

\title{
EUVOLAEMIC HYPONATRAEMIA.
}

\section{RESULTS OF A LARGE PROSPECTIVE STUDY}

Authors: Martín Cuesta, Aoife Garrahy, David Slattery, Saket Gupta, Anne Marie Hannon, Hannah Forde, Karen McGurren, Mark Sherlock ${ }^{1}$, William Tormey², Christopher J Thompson Institution: Academic Department of Endocrinology, Beaumont Hospital/RCSI Medical School, Dublin, Ireland.

${ }^{1}$ Department of Endocrinology, The Adelaide and Meath Hospital, Dublin/ Trinity College, Dublin, Ireland

2Department of Chemical Pathology. Beaumont Hospital/RCSI Medical School, Dublin, Ireland.

\section{INTRODUCTION}

-The syndrome of inappropriate antidiuresis (SIAD) is the commonest cause of hyponatraemia. Data on SIAD is mainly derived from retrospective studies, often with poor

ascertainment of the minimum criteria for the correct diagnosis. - Reliable data on the incidence of adrenal failure in SIAD is unavailable.

- The aim of the study was to define the prevalence of undiagnosed adrenal insufficiency.

\section{PATIENTS}

This is a prospective, single centre, observational study of all consecutively hospitalized patients with SIAD, with hyponatraemia $(\leq 130 \mathrm{mmol} / \mathrm{L})$ in Beaumont Hospital, from January 1st to October 1st 2015.

\section{INVESTIGATION OF ADRENAL}

$$
\text { FUNCTION }
$$

If the diagnostic parameters suggested SIAD, thyroid function tests and $0900 \mathrm{~h}$ plasma cortisol measurements were requested. A $0900 \mathrm{~h}$ cortisol $>300 \mathrm{nmol} / \mathrm{l}(>10.9 \mathrm{mcg} / \mathrm{dl})$ was regarded as unlikely to reflect adrenal insufficiency of sufficient severity to cause hyponatraemia.

Where $0900 \mathrm{~h}$ plasma cortisol was $<\mathbf{3 0 0} \mathbf{n m o l} / \mathbf{l}(<\mathbf{1 0 . 9}$ $\mathbf{m c g} / \mathbf{d l}$ ), a short synacthen test was performed. In addition, a short synacthen test was performed in patients with $0900 \mathrm{~h}$ serum cortisol between $300(10.9 \mathrm{mcg} / \mathrm{dl})$ and $414 \mathrm{nmol} / 1$ (15 $\mathrm{mcg} / \mathrm{dl}$ ) if other parameters, such as hypotension or hypoglycaemia, were suggestive of adrenal insufficiency. Normal response was defined as a cortisol peak above 500 $\mathrm{nmol} / 1,30$ minutes post synacthen injection.

In patients with chronic oral glucocorticoid, SIAD patients were regarded as steroid deficient if they fulfilled the following criteria:

1) Prolonged adrenosuppressive doses of oral steroids ( $>4 \mathrm{mg}$ prednisolone or equivalent).

2) There was failure to intervene with stress dose of steroids, as per good clinical practice.

3) There were additional clinical features, such as hypotension, hypoglycaemia or failure to respond to resuscitative measures, which suggested steroid insufficiency.

4) There was clear evidence of immediate improvement in all of the above with steroid therapy.

\section{RESULTS}

Data were obtained prospectively in 1323 patients who were admitted with hyponatraemia $\leq 130 \mathrm{mmol} / \mathrm{L}$, or who developed hyponatraemia during hospital admission. $573(43.3 \%)$ admission episodes in 516 patients were assigned an initial diagnosis of SIAD, based on classic diagnostic criteria.

\begin{tabular}{|c|c|c|c|}
\hline & $\begin{array}{c}\text { Diagnostic criteria } \\
\text { obtained n (\%) }\end{array}$ & $\begin{array}{l}\text { Laboratory } \\
\text { reference range }\end{array}$ & $\begin{array}{l}\text { Patient results } \\
\text { Median and (IQR) }\end{array}$ \\
\hline $\begin{array}{l}\text { Plasma Sodium } \\
(\mathrm{mmol} / \mathrm{l})\end{array}$ & $573 / 573(100 \%)$ & $133-146$ & $128(126,130)$ \\
\hline Urea (mmol/l) & $573 / 573(100 \%)$ & $2.5-7.8$ & $5.1(3.9,6.6)$ \\
\hline UOsm (mOsm $/ \mathrm{kg})$ & $498 / 573(86 \%)$ & $>100$ & $437(340,545)$ \\
\hline UNa (mmol/l) & $491 / 573(86 \%)$ & $>30$ & $50(31,83)$ \\
\hline TSH (mU/l) & $524 / 573(91 \%)$ & $0.5-4.2$ & $1.4(0.89,2.3)$ \\
\hline $\begin{array}{l}\text { 09:00 h Plasma } \\
\text { Cortisol (nmol/l) }\end{array}$ & 413/492 (84\%) & $>300$ & $453(371,563)$ \\
\hline
\end{tabular}

\section{EUVOLAEMIC HYPONATRAEMIA NOT DUE TO SIAD}

40/476 (8.4\%) patients had a $0900 \mathrm{~h}$ plasma cortiso concentration $<300 \mathrm{nmol} / 1$, and underwent a short synacthen test. In addition, $8 / 476(1.6 \%)$ patients with $0900 \mathrm{~h}$ cortisol above $300 \mathrm{nmol} / 1$ had additional features (hypotension, nausea unexplained weight loss) suggestive of adrenal failure and also had synacthen testing.

48 short synacthen tests were performed in total in the cohort of patients. 10/48 (21\%) patients had a peak cortisol post synacthen $<500 \mathrm{nmol} / \mathrm{L}$, all of whom had $0900 \mathrm{~h}$ cortisol $<300$ $\mathrm{nmol} / 1$.

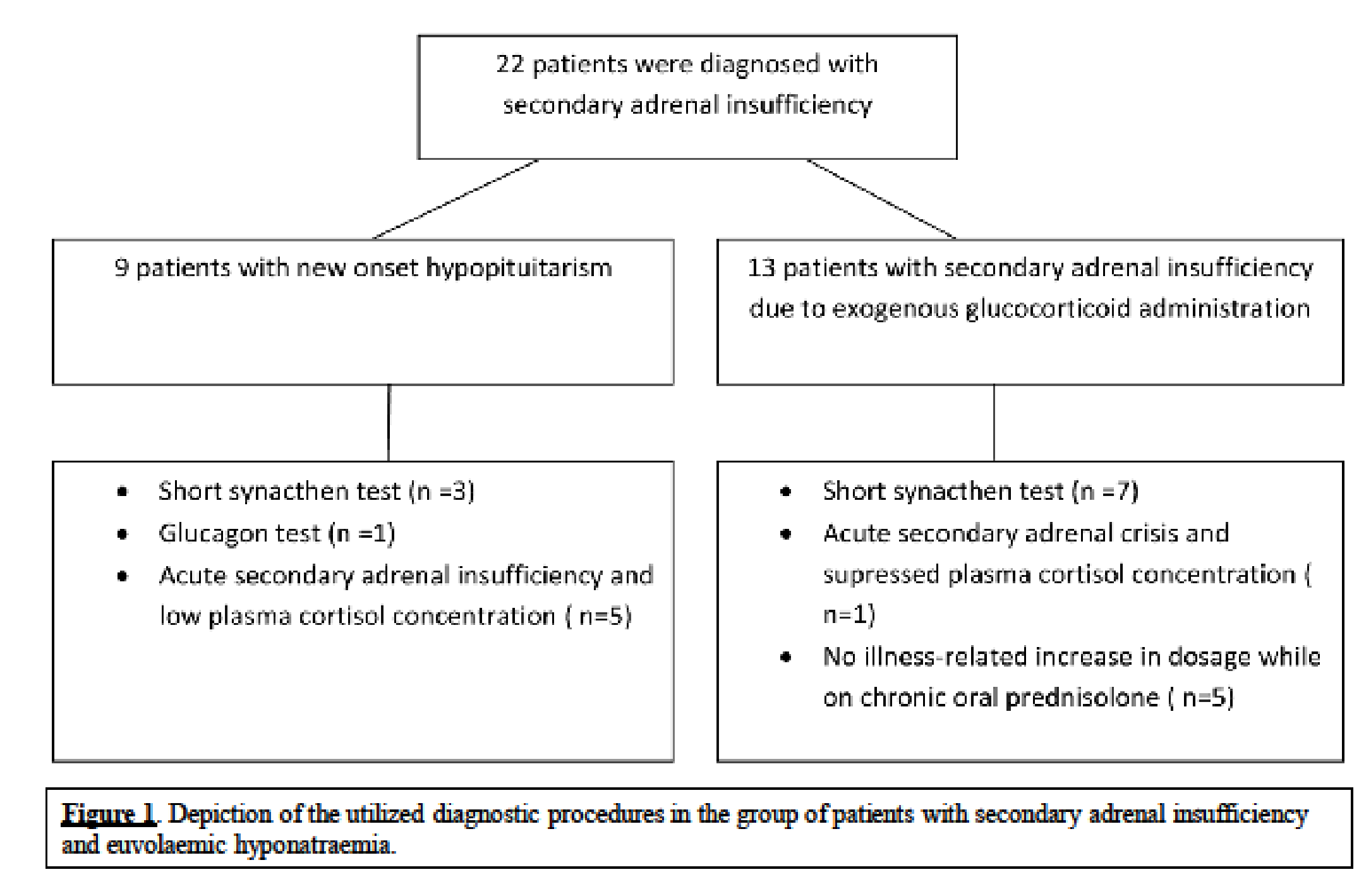

EUVOLAEMIC HYPONATRAEMIA DUE TO NEW ONSET HYPOPITUITARISM

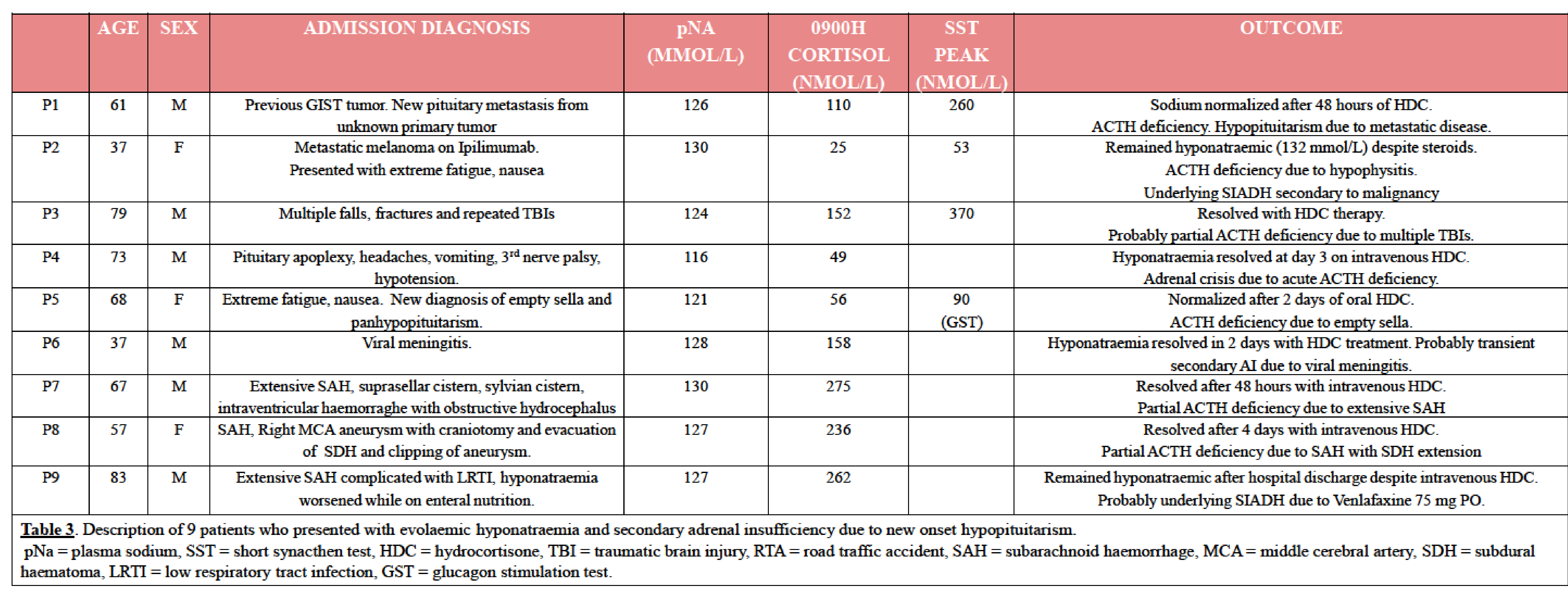

EUVOLAEMIC HYPONATRAEMIA ON A BACKGROUND OF CHRONIC EXOGENOUS GLUCOCORTICOID ADMINISTRATION

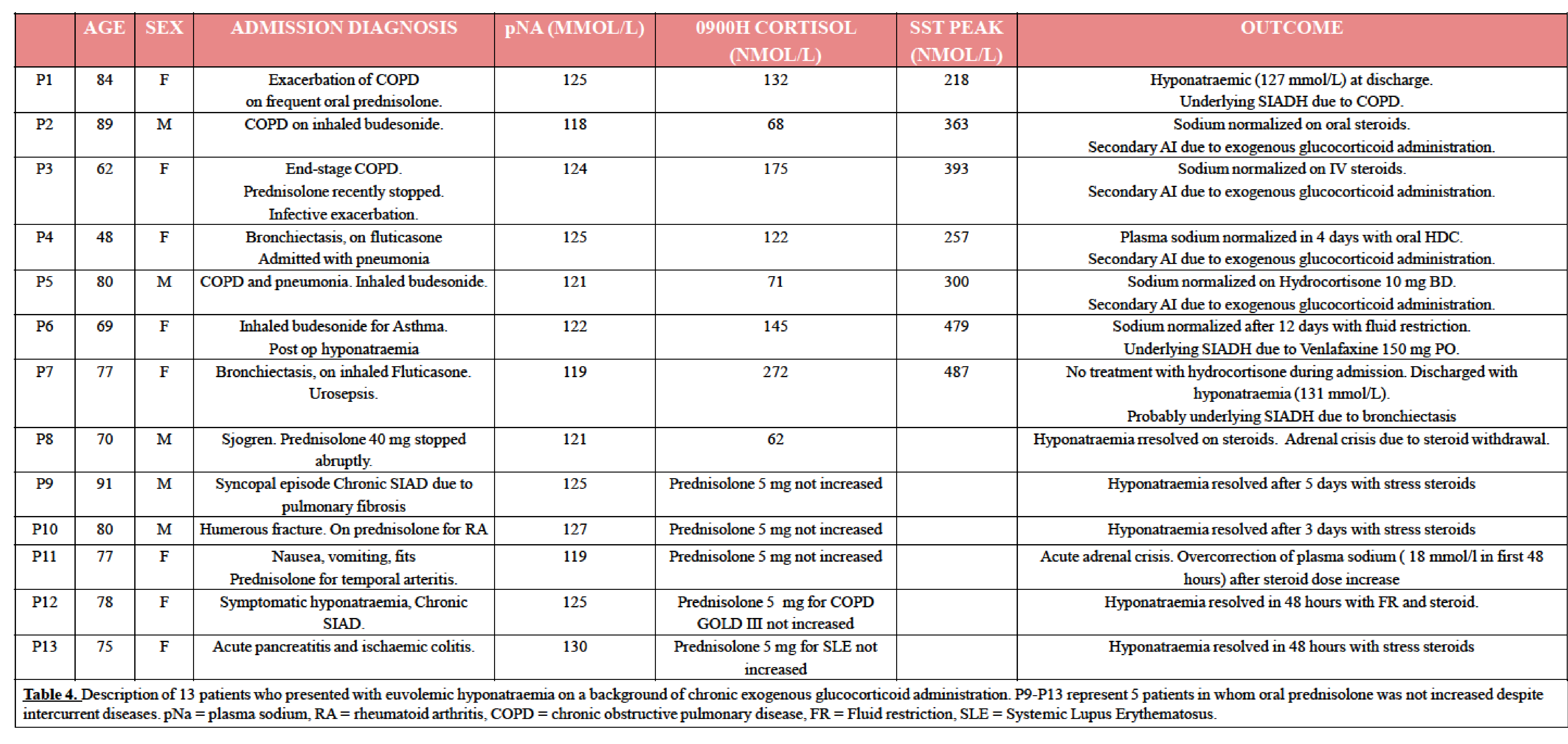

CONCLUSIONS

-SIAD is a diagnosis of exclusion. All patients must be investigated to rule out secondary adrenal insufficiency. -In a large, prospective and well-defined cohort of euvolaemic hyponatraemia, undiagnosed secondary adrenal insufficiency co-occurred in $\mathbf{3 . 8 \%}$ of cases initially diagnosed as SIAD.

-Undiagnosed pituitary disease was responsible for $\mathbf{1 . 5 \%}$ of cases presenting as euvolaemic hyponatraemia

-The relationship between hypopituitarism and premature death is well established, and adrenal crisis in response to acute illness is a major cause of excess mortality in patients with hypopituitarism and adrenal insufficiency.

-Screening for adrenal insufficiency in hyponatraemia not only focuses treatment of the acute episode, but also enables us to identify strategies to improve long term welfare. 